\title{
TOMISMO $Y$ JESUITISMO EN LOS TRIBUNALES ESPAÑOLES EN VÍSPERAS DE LA EXPULSIÓN DE LA COMPAÑÍA
}

\section{María del Carmen IRLES VICENTE}

Universidad de Alicante

En un articulo publicado hace dos décadas;, el profesor Olaechea reproducia la valoración que un anonimo informante transmitio al secretario de Gracia y justicia Manuel de Roda ${ }^{2}$, en agosto de 1765, sobre las tendencias filojesuiticas, o contrarias a la Compañía, de la mayor parte de los ministros de los Consejos, Chancillerias y Audiencias del Reino. Tomando como punto de partida las noticias que ese documento suministra, nos proponemos valorar tanto el peso que cada una de las mencionadas fuerzas tenía en visperas de la expulsión de los jesuitas, como la posible incidencia que los datos vertidos en el escrito tuvieron en la configuración de la posterior trayectoria política de los referidos personajes (ascensos más o menos rápidos, empapelamientos, etc.).

Como señalaba el profesor Olaechea en el mencionado articulo, durante el siglo XVIII "el nombre de thomista, que era colectivo, llegó a sonar publicamente como "opuesto a jesuita", esio es, adversario de las opiniones teológico morales sostenidas colectivamente por la Compañia de Jesüs, como cuerpo religioso".". Siendo esto así, no es de extrañar que en un momento en el que se tramaba la aniquilación de la Compañía, se intentase averiguar con qué fuerzas contaba ésta entre los magistrados de los principales tribunales del país.

En el verano de 1765 catorce de los veinticinco ministros del consejo de Castilla -incluido el gobernador-, esto es, el $56 \%$, fueron calificados como jesuitas; también los secretarios de la Cámara militaban en dicho bando. Dentro de este grupo, sin embargo, se distinguian diferentes grados de compromiso con la Compañía; así, mientras unos eran denominados simplemente jesuitas ${ }^{4}$, a otros se aplicaba el 
apelativo de jesuitas de cuarto voto ${ }^{5}$, existiendo un último grupo en el que la vinculación a la Compañía necesitaba de cierta explicación; así, por ejemplo, Pedro Colón de Larreategui, a quien "le manda su mujer, que es toda jesuita", o el marqués de Monterreal, quien pese a tener dos hermanos carmelitas descaizos, y confesarse "en esta Religión, es jesuita desde que casó su hijo con la marquesa de Valverde, sobrina de los PP. Urbina y Villafañe, jesuitas de la provincia de Castilla la Vieja"'.

Un claro ejemplo de militancia pro-jesuita la podemos encontrar en Manuel Ventura Figueroa, definido como "profeso y voceador, y tan adicto a los jesuitas que un beneficio de 300 ducados de la casa de Ribadavia. con que principió su fortuna. le tiene cedido de limosna al colegio de jesuitas de Santiago".

Frente a ese mayoritario $56 \%$, un $20 \%$ era calificado como tomista ${ }^{7}$. Aunque no con total grado de frabilidad, podía ser incluido en este grupo Antonio Francisco Pimentel, que habia sido jesuita en su día, "pero ahora es converso y no asiente bien de sus máximas"; Pedro Rodríguez Campomanes, que negaba ser jesuita; y el marqués de Montenuevo, quien pese a su parentesco con el marqués de Monterreal eran primos-, y haber mantenido una estrecha relación con el marqués de la Ensenada mientras ocupaba la presidencia de la Chancilleria de Granada, existían "bastantes motivos para creer no es jesuita", asi como la certeza de ser su mujer "tomista muy segura".

Habia otro grupo que resultaba dudoso, y en el que cabría incluir a Francisco José de las Infantas a quien, pese a definirse como tomista, "se han visto algunos votos contrarios a este concepro, y en mediando colegial de San Ildefonso no distingue escuelas" ; y José del Campo, que aunque decia ser tomista, "se confiesa y dirige por los PP. jesuitas".

Por último, cabe consignar a aquellos individuos que, al menos aparentemente, no militaban en ninguna de las dos escuelas antagónicas, como Francisco Salazar y Agüero, que era calificado como "indiferente, pero menos adicto a los jesuitas".

Si en el consejo de Castilla eran mayoría los seguidores de la Compañía, otro tanto pasaba en el de Indias ${ }^{9}$, Órdenes ${ }^{10}$ y Hacienda ${ }^{1 i}$; sólo el consejo de Inquisición parecía substraerse a la influencia de los jesuitas ${ }^{12}$.

En la Sala de Alcaldes de Casa y Corte las fuerzas estaban más o menos parejas, coexistiendo un $50 \%$ de individuos calificados como jesuitas ${ }^{1.3}$, con otro $50 \%$ que respondía a los apelativos de tomista, "no es jesuita", anti-jesuita. etc ${ }^{14}$. El juicio más llamativo es el que se hacía respecto a José Moreno Beltrán y Fernando José de Velasco, ambos jesuitas profesos; del primero se decía que era el favorito del Gobernador del Consejo -a la sazón Diego de Rojas y Contreras, obispo de 
Cartagena-, "quien echará el resto a colocarle en una de las presidencias si hubiera vacante, que éste es su fin para asegurar a los jesuitas la primer silla de uno de aquellos tribunales, asi como lo está hoy la de Castilla y las de los demás Consejos"; de nuevo se aludía a la presidencia de los tribunales al hacer referencia a Fernando José Velasco, de quien se aseguraba "no convendría para presidente de las Chancillerias. que es todo su deseo, o entrar en el Consejo", pues en cualquier parte seria dominado por los jesuitas "para todo lo graciable"; por contra, se insistía que "en una plaza de Órdenes, que resiste, es donde pudiera colocársele, pues en indias. - Castilla. o Presidencia, pudiera tener inconveniente por lo expuesto, asegurándose como notorio no es para fiscal de la Sala".

En las Chancillerías la presencia de jesuitas era arrolladora, sobre todo en Granada, con cerca del $85 \%$ de sus ministros ${ }^{15}$; en Valladolid se mantenía en unas cotas inferiores, situándose en torno al $36 \%$, siendo de destacar asimismo en esta última la existencia de un $12 \%$ de individuos que se mostraban indiferentes "en la inclinación de religiones"16.

La información disponible sobre las Audiencias era muy heterogénea, oscilando entre los casos extremos de La Coruña ${ }^{17}$, Oviedo ${ }^{18}$. Valencia ${ }^{39}$ y Mallorca ${ }^{26}$, donde se conocian las inclinaciones de sus integrantes, y los de Zaragoza, Barcelona, Sevilla y Canarias, donde la inexistencia de datos era prácticamente total; la primera situación era compartida, asimismo, por el tribunal navarro ${ }^{21}$.

Una vez expuesta cuál era la composición de los tribunales españoles en visperas de la expulsión de los jesuitas, pasaremos a esbozar la posterior trayectoria politica de sus integrantes para verificar de esta forma si las alabanzas o descalificaciones formuladas por el anónimo informante de Roda fueron tenidas en cuenta y determinaron una más o menos rápida ascensión en su carrera profesional. Como es obvio, no nos detendremos a analizar la trayectoria de los consejeros, no sólo porque en el caso de los miembros del consejo de Castilla habían llegado ya a la cúspide de la pirámide de ascensos; tampoco, y en el caso de los restantes consejeros, porque su ya corta esperanza de vida y la falta de metas -el logro de un puesto en el de Castilla o en la Cámara- no resultarian ilustrativos. Por contra, en el caso de los miembros de Audiencias y Chancillerias, donde todavia quedaban cargos que escalar -en mayor o menor medida según el puesto que desempeñasen en ese momento-, se puede comprobar perfectamente si el informe en cuestión fue tenido en cuenta o pasado por alto en un momento en que desde el gobierno se tomaban medidas para acabar no sólo con los jesuitas, sino también con todo lo que tuviera relación con la Compañía.

En la Audiencia valenciana el calificativo de jesuita aplicado al regente, Andrés Simón Pontero, no parece que jugara en su contra a la hora de una posible promoción; de hecho, consultado en dos ocasiones en tercer lugar para una plaza del consejo de Castilla en 1768 y 1769 , la obtuvo en mayo del año siguiente cuando 
ocupaba el primer lugar en la terna presentada por la Cámara al rey para sustituir al fallecido Francisco José de las Infantas ${ }^{22}$.

Los oidores Jose Moreno Alvarado y Eugenio Miguel Muñoz, pese al distinto calificativo con que fueron distinguidos ${ }^{23}$, siguieron una trayectoria pareja hasta su jubilación en 1772. Los informes practicados por personalidades como Juan de Isla, Antonio Aperregui, Marcos Jimeno -todos ellos regentes de dicha Audiencia en diferentes momentos- o el Arzobispo de Valencia coincidieron en calificarlos como sujetos literatos, aplicados, así como capaces de desempeñar mayores empleos; sin embargo, ninguno de ellos dejó la Audiencia para promocionar a un empleo superior: su resistencia a abandonar un territorio donde se hallaban fuertemente $\operatorname{arraigados}^{24}$, y su deplorable estado de salud, podrían explicar esa falta de ascensos. En el caso de Moreno Alvarado decía Juan José de Eulate -oidor como él en el tribunal valenciano- que "cuenta ya con 80 años, y aunque en lo animal está bastante robusto para tan avanzada edad, pero padece una extraordinaria debilidad de potencias, de modo que puedo asegurar a $V$. Ex. que nunca entiende los hechos, aun los más claros, y asi decide a ciegas, condenando o absolviendo indistintamente. sin formar concepto fijo" 25 ; no es de extrañar, por tanto, que aun contando con la cualidad de "tomista", no lograra ascender a un puesto de mayor responsabilidad.

Aunque en el cursus honorum de los dos individuos anteriores no se perciben diferencias significativas, de hecho la militancia en una u otra escuela condicionó en algunas ocasiones la evolución posterior, tal y como se puede comprobar analizando la trayectoria de Francisco Locella.

Calificado de "tomista insigne y gran letrado" en 1765. Locella fue propuesto en junio del año siguiente en primer lugar para la regencia de Aragón, cargo para el que fue designado. No pararía mucho tiempo, sin embargo, en el tribunal aragonés, ya que en julio de 1767 era consultado para una plaza del consejo de Castilla, repitiéndose su nombre en nuevas ternas presentadas por los meses de septiembre y octubre, y logrando ser seleccionado finalmente en abril de 1768; cuatro años más tarde moría, poniendo así fīn a una fulgurante carrera.

Aunque el ascenso no fuera tan meteórico como en el caso anterior, también Manuel Villafañe, un "tomista insigne", dejó la Audiencia de Valencia al serle concedida en 1770 una plaza de alcalde honorario de Casa y Corte, asi como ser designado director de los estudios reales de San Isidro de Madrid. Tres años más tarde pasaba al consejo de Hacienda en sustitución de Miguel Joaquín de Lorieri; desde ese momento únicamente fueron necesarias dos consultas de la Cámara para que Villafañe obtuviera un puesto en el consejo de Castilla, cargo que ocupó a partir de 1775 por fallecimiento de Pedro de Avila y Soto.

Pese a haber quedado enmarcado en la facción contraria, Jacinto Miguel de Castro, un convencido seguidor de las ideas jesuiticas -"jesuita, y lo ha sido 
siempre"-, fue ascendido a la regencia mallorquina en octubre de 1765. cuando tan sólo llevaba cuatro años como oidor en Valencia. Sin embargo, a partir de ese momento atravesó serias dificultades para lograr un ascenso, que no liegó hasta 1770, tras ser consultado en cinco ocasiones para el consejo de Castilla en todas las posiciones posibles ${ }^{26}$, y ser expulsado de Mallorca por el capitán general marques de Alós ${ }^{27}$. Finalmente logró una plaza en el consejo de Indias en 1770, desde cuyo tribunal pasó, dos años más tarde, al de Castilla. en sustitución del recientemente fallecido Lope de Sierra y Cienfuegos.

Aunque no consiguiera un puesto en el consejo de Castilla, los pasos seguidos por Teodomiro Caro de Briones fueron similares a los de su compañero. Cuando apenas llevaba dos años como oidor en Valencia, Caro fue consultado -el 16 de marzo de 1765- en tercer lugar para la regencia de Mallorca, plaza que finalmente obtuvo el antedicho Castro. Este fracaso inicial no desanimó a la Cámara, que continuó presentando su nombre en años sucesivos en diferentes ternas para todas las regencias peninsulares: en mayo de 1766 para la de Asturias, en junio de este mismo año para la de Aragón, y en noviembre y diciembre de 1768 para la de Sevilla y Galicia. respectivamente. Caro también fue consultado a lo largo de 1767 y 1769 para, al menos, cinco plazas de alcalde de Casa y Corte, obteniendo siempre el mismo resultado negativo. Finalmente, en la primavera de 1770 logró la designación para cubrir la vacante dejada en la regencia de Asturias por promoción al Consejo de Antonio Veyán.

Pese a que durante su estancia en Valencia Caro de Briones sirvió "su plaza con la mayor limpieza, integridad, celo y utilidad pública"28, habian sido necesarias doce consultas de la Cámara de Castilla para lograr este ascenso; tampoco en adelante, y pese al empeño puesto por los camaristas ${ }^{20}$, consiguió obtener la tan apetecida plaza de consejero de Castilla, debiendo conformarse con ingresar en el de Indias en junio de 1773, para sustituir al fallecido Manuel Pablo de Salcedo, destino en el que murió al año siguiente ${ }^{30}$.

Si los individuos que ocupaban las plazas civiles de la Audiencia valenciana tuvieron ascensos relativamente rápidos, y bastante notorios ${ }^{31}$, la práctica toralidad de los fiscales y alcaldes del crimen finalizaron su carrera en unos escalones bastante bajos, ya porque les sorprendiera la muerte -como en el caso de Pedro Ignacio Llanzol de Romani, el unico que fue calificado de "tomista", Miguel Jurado de los Reyes o Bernardo Torrijos ${ }^{32}$-, ya porque la coletilla "jesuita", que el anónimo informante puso junto a sus nombres, pesara demasiado sobre sus carreras. Juan Andrés Losada Temes, el que logró ocupar un puesto más elevado, falleció en 1789 siendo oidor de la Chancillería de Valladolid, empleo al que había accedido en 1774 tras servir nueve años como oidor en la Audiencia valenciana; Ignacio de Vargas y Jose Maria Reina ${ }^{3.3}$, por su parte. sólo llegaron a alcanzar sendas plazas civiles en el tribunal de la ciudad del Turia. 
Los magistrados de la Audiencia de Mallorca, calificados en su conjunto de jesuitas. tampoco lograron ascensos notables ${ }^{34}$; sólo el regente, que había sido ya designado fiscal del consejo de Indias a comienzos de 1765, llego a ocupar una plaza en el más importante tribunai de la monarquía, el de Castilla, a partir de 1766; ninguno de los otros ministros llegarian a destino similar. Jaime Serra y Nadal se jubiló en 1774; el fiscal Manuel León Santos falleció en 1765; Buenaventura Ferrán y Felipe Miralles Garcés de Marcilla fueron promovidos en 1768 y 1774 , respectivamente, a oidores de la Audiencia de Cataluña y Aragón, en cuyos destinos les sobrevino la muerte en 1806 y 1802. Tan sólo Felipe Soler Bargallo logró su paso a la sala de Alcaldes de Casa y Corte tras ser consultado en primer lugar en junio de 1767; aunque también figuró en la terna presentada el 27 de febrero de 1771 para la presidencia de la Chancilleria de Valladolid, no fue designado, permaneciendo en la Corte hasta 1779 en que cambio la carrera judicial por la eclesiástica tras obtener una canonjía en la Santa Iglesia de Valencia.

El regente de la Audiencia de Galicia, Juan Fernando Barrueta, pese a ser repetidamente consultado, desde 1767, para diferentes plazas del consejo de Castilla, no logró acceder al mismo, debiendo conformarse con terminar sus días en el consejo de Órdenes, al cual se incorporó en 1768. Sólo a su militancia "jesuítica" cabe achacar este atraso en la carrera, ya que los informes que sobre su persona se redactaron incidían en calificarlo como "ministro hábil, celoso y de buena conducta", así como destacar que era "sobresaliente en literatura, de notoria habilidad, buen genio, maduro juicio, porte, rectitud y desinterés, y asistente al tribunal" ${ }^{15}$.

Tampoco Juan Luis Jiménez de Saboya, uno de los tres magistrados de la Audiencia gallega que no comulgaba con el pensamiento de la Compañía, logró ascender en su carrera pese a las ideas que profesaba, ya que falleció en dicho destino. En este caso, sin embargo, cabe hacer algunas matizaciones, ya que probablemente su larga permanencia en el tribunal coruñès fuera solicitada por el propio interesado, merced a su arraigo en la zona y los ligámenes familiares contraídos; en esa dirección apuntan los informes practicados por José Manuel de Villena y Francisco Antonio Sánchez Salvador en 1753 y $1760^{36}$.

Como Jiménez de Saboya, acabaron también sus días en el tribunal gallego Alonso Pascual de Montemayor, Fernando Felipe de Castro y Jimeno, Pedro de la Puente, Manuel Hermida y Porras, Jerónimo Romero ${ }^{37}$, y Bartolomé Balledor, si bien en este último caso no faltaron consultas de la Cámara recomendando su designación como consejero de Órdenes -ocho entre los años 1767 y 1773 -

Gregorio Portero de Huerta fue, junto a Marcos Argaiz, uno de los escasos magistrados de la Audiencia de Galicia que tuvo una larga y provechosa carrera. En 1765 era alcalde del crimen de dicho tribunal, empleo del que fue ascendido a oidor al año siguiente para cubrir la vacante dejada por fallecimiento de Manuel Hermida y Porras. En años sucesivos su nombre figuró en sendas ternas presentadas por la 
Cảmara para la regencia de İas Audiencias de Valencia, Sevilla y Asturias, asi como el consejo de Navarra; sin embargo, fue para cubrir plazas de Alcalde de Casa y Corte cuando los camaristas recurrieron repetidamente a él $\left.\right|^{38}$, siendo finalmente designado en 1773, tras contar con la recomendación del marqués de Grimaldi ${ }^{39}$.

Después de cinco años en los tribunales de la Corte, Gregorio Portero pasó, en 1778, a presidir la Chancillería de Valladolid, donde permaneció hasta 1785 , momento en que se incorporó al consejo de Castilla en sustitución de Antonio Veyán, recientemente fallecido ${ }^{40}$.

Marcos Argaiz, que se hallaba sirviendo la fiscalía de lo civil desde 1761, ascendio a finales de 1766 a una plaza de oidor de la misma Audiencia. Aunque en 1772 estuvo propuesto para el consejo de Órdenes, fueron las repetidas consultas en las que su nombre figuraba como candidato a una plaza de alcalde de Casa y Corte una en 1772 y tres en 1773-, las que acabaron por posibilitar su incorporación a este tribunal en julio de 1773. Algunos años más tarde -agosto de 1778- sería promovido al consejo de Castilla, tras figurar en cuatro ternas para dicho empleo, y después de haber sido pasada por alto la que le colocaba en primer lugar para la presidencia de la Chancillería de Granada.

También el otro fiscal gallego, José Antonio Giraldo, subió con rapidez en la carrera, condicionado, posiblemente, por la calificación de "tomista", ya que a lo largo de 1769 fue consultado en tres ocasiones para plaza de oidor de la Chancilleria de Granada, destino que no obtuvo, aunque sí la regencia de Canarias. Su pronto fallecimiento, en 1774, le privó de seguir ascendiendo en una carrera que se preveía provechosa, ya que en julio de 1773 y junio de 1774 fue consultado, respectivamente, para la presidencia de Granada y una de las fiscalías del consejo de Castilla.

Frente a los casos analizados hasta ahora, consideraciones totalmente ajenas a la militancia en favor o contra de la Compañía se perciben a la hora de determinar la promoción de los ministros de la Audiencia de Oviedo; ejemplo paradigmático puede ser el de Jerónimo Velarde Sola.

Aunque calificado como "factor de jesuitas y estrechamente unido a ellos", Jerónimo Sola, que desde 1762 venía realizando las tareas de fiscal de la Audiencia de Oviedo, fue ascendido a oidor de la Chancillería de Valladolid en 1766, la segunda vez que, en el plazo de un mes, era propuesto para dicho cargo ${ }^{41}$. De este empleo pasó, en 1773. a la regencia de la Audiencia de Mallorca $^{42}$, y de ésta, al año siguiente, a la de Barcelona. Apenas tres años más tarde entraba a presidir la Chancillería de Granada, puesto que dejó en 1784 para incorporarse al consejo de Castilla, donde permaneció hasta su muerte, sobrevenida en enero de 1799, si bien entre enero de 1787 y comienzos de 1792 había desempeñado, asimismo, las tareas de gobernador de la sala de Alcaldes de Casa y Corte. 
Los ascendientes familiares de Velarde -era nieto y sobrino. respectivamente, de los consejeros de Indias Tomás y Jerónimo de Sola- y el buen juicio que siempre mereció su persona ${ }^{43}$. debieron pesar más que la descalificación que hiciera en 1765 el informante de Roda.

Otro de los ministros de la Audiencia asturiana que, pese a ser sospechoso de jesuita ${ }^{44}$, logró completar el ciclo de ascensos fue Pedro Manuel Fernández Villegas. Promovido a oidor de la Chancillería de Valladolid en 1766, Villegas apenas si tardó un año en ser destinado a la regencia de Canarias, de donde pasó en 1770 al consejo de Castilla ${ }^{45}$. Como en el caso de Velarde, en su posterior promoción debieron jugar un papel muy importante loṣ favorables informes que sobre su conducta manejó la Cámara, como el practicado en 1766 por el regente de la Audiencia de Asturias, reducido a señalar que:

"este ministro tiene prendas muy recomendables por su genio. virtud, suficiencia y especial aplicación y literatura, portándose en todo con rectitud ${ }^{140}$.

Parecida trayectoria a la de los dos magistrados anteriores tuvo Pedro Prudencio Taranco. Oidor de la Audiencia de Oviedo desde 1758, tras ser consultado en diferentes posiciones para alcalde de Casa y Corte y regente de la Audiencia de Galicia, obtuvo en julio de 1769 el primero de dichos empleos ${ }^{47}$. Un año más tarde volvía a aparecer su nombre en las ternas presentadas por los camaristas al monarca, esta vez para cubrir vacantes en el consejo de Órdenes. cargo para el que fue finalmente designado en 1772; ocho años más tarde lograba una plaza en el consejo de Castilla, en cuyo desempeño falleció en 1786.

También Pedro González de Mena, un "ministro docto y de mucho lucimiento", y a quien no se le habia notado "especial adhesión a los jesuitas", se incorporó al consejo de Castilla en 1772, un año antes de que le sobreviniera la muerte, si bien como fiscal ${ }^{48}$; con anterioridad habia desempeñado este mismo empleo en el consejo de Indias, tras ser designado en 1767.

En la trayectoria de los ministros de la Audiencia de Asturias analizados hasta el momento, que resulta bastante similar, no parece haber influido en sentido negativo la calificación de jesuitas con que fueron mayoritariamente distinguidos; hemos dejado conscientemente para el final el caso más curioso: el de Cristóbal Vivero Sánchez Calderón, el único ministro calificado de "antijesitita" en dicho tribunal.

En el informe dirigido a Roda se decía que por su militancia antijesuita había sido muy perseguido por estos Padres, "porque no le pudieron manejar, y por lo mismo el márqués del Campo de Villar le atendió muy poco", si bien se reconocía que era "ministro integro. muy docto y justificado". La suerte de Vivero no mejoró 
en los años siguientes, pues pese a ser consultado reiteradamente para oidor de la Chancillería de Granada a lo largo de 1769 -en tres ocasiones-, de la de Valladolid en 1776 y 1777, y regente de la Audiencia de Canarias en 1770 y 1775, no logró un ascenso hasta 1777 cuando, por fallecimiento de Jacinto Bretón, se incorporó al tribunal vallisoletano.

Pese a que los informes sobre su preparación y conducta se mostraron reiteradamente positivos ${ }^{49}$, Cristóbal Vivero permaneció relegado de los puestos de mayor responsabilidad; de hecho, cuando falleció en 1792 continuaba desempeñando su plaza de oidor en Valladolid.

El regente, Manuel Verdeja, calificado como "jesuita, pero ministro imparciai en puntos de justicia", fue el único de los magistrados de la Audiencia de Oviedo que no llegó a ascender, ya que falleció en abril de 1766.

En el tribunal navarro, por contra, los méritos de su regente, José Contreras, que era "más inclinado a tomistas que a jesuitas", fueron premiados con la presidencia de la Chancillería de Valladolid en junio de $1767 \mathrm{y}$, cuatro años más tarde, con una plaza en el consejo de Castilla. No acabó aquí su carrera, ya que en noviembre de 1789 se le expedía título de camarista, logrando de esta forma alcanzar la cúspide de la pirámide de poder para un magistrado.

Juan Matías de Azcárate, un pamplonés de quien no se sabia "ciertamente su inclinación, pero corre con la Compañía", presenta una de las carreras más sobresalientes. En 1765 era alcalde del consejo de Navarra, cargo al que se había incorporado en 1757 y del que pasaría en 1771 a la plaza de oidor. Cuatro años más tarde, en 1775, obtuvo la regencia de la Audiencia de Asturias, solicitando al año siguiente su incorporación a alguno de los consejos de la monarquía. Aunque hasta ese momento Azcárate había ido consiguiendo de manera inmediata los cargos para los que iba siendo propuesto. pese a figurar en cinco ternas presentadas para sendas plazas del consejo de Castilla desde 1780 a 1784 , fue la presidencia de Granada la que obtuvo este último año; tras tres años en dicho destino logró por fín su incorporación al Consejo $y$, ya en 1796, ser uno de los miembros de la Cámara.

Como en otras de las carreras que venimos analizando, el factor familia debio resultar decisivo para favorecer los ascensos de Azcárate, sobre todo por parte de su mujer, ya que estaba casado con María Rafaela de San Cristóbal, condesa de San Cristóbal e hija del consejero de Guerra Julián de San Cristóbal.

Aunque no lograra un puesto de camarista, también Juan Tomás Micheo accedió al consejo de Castilla en 1776. Como le sucediera a Azcárate, Micheo -un navarro del valle de Baztán- apenas tuvo dificultades para ascender de la plaza de alcalde de Corte del consejo de Navarra, que ocupaba desde 1758, a la de oidor en 1768, si bien unos meses antes fue propuesto para otra en la Chancillería de 
Valladolid. Poco después, en 1771, pasaba como regente a la Audiencia de Zaragoza, donde permanecería por espacio de cinco años hasta conseguir la promoción al Consejo tras figurar su nombre en ocho consultas.

Juan Ascensio de Ezterripa, un navarro "afecto a la Compañia", necesito de múltiples consultas de la Cámara para lograr un ascenso ${ }^{5(i)}$, que no se produjo hasta 1774 cuando entró a formar parte de la sala de alcaldes de Casa y Corte en la vacante dejada por Miguel Gálvez, que había sido destinado al consejo de Guerra. Cuatro años más tarde también Ezterripa accedería a un consejo, en este caso el de Órdenes, en el que falleció en 1780.

Los individuos reseñados son los únicos que lograron promocionar, ya que la mayor parte de los ministros del consejo de Navarra permanecieron en dicho tribunal hasta el fin de sus días, independientemente de que éste se produjera en la década de los sesenta o en fechas más avanzadas. Pese a "su inclinación al Carmen calzado", y no conocérsele "odio ni afición a la ciencia media", José Matías Lanciego, oidor del consejo de Navarra, terminó sus dias en dicho tribunal en 1779; también a José Fernando Pagola, "carmelita calzado y descalzo, y enemigo de la ciencia media", le sobrevino la muerte en 1771 cuando era alcalde de Corte en dicho tribunal. Otro tanto sucedió con Ignacio Azcona quien, por contra, era "afecto a la Compañia"isi. Agustín Eguía Ramírez de Arellano, un pamplonés que era "todo jesuita", fue jubilado el 27 de junio de 1792 debido a su total falta de vista ${ }^{52}$. Julián Ozcariz, pese a ser consultado para los corregimientos de Guipúzcoa y Vizcaya, desarrolló toda su carrera en el tribunal navarro, en primer lugar como fiscal, más tarde como alcalde de Corte y, finalmente, como oidor, empleo del que obtuvo la jubilación en 1804. Miguel Jacinto Olazagutia, otro navarro del que, como en el caso de Ozcariz, no se conocían sus inclinaciones -"no se sabe que sea de una u otra escuela"-, falleció en 1768 .

Aunque la mayor parte de los magistrados que no llegaron a abandonar el tribunal navarro ocupaban plazas de natural ${ }^{53}$, también Leopoldo Pavía y Rato, un alicantino emparentado con el obispo de Córdoba Tomás Rato y con el canónigo de Valencia Juan Bautista Rato, y que en cuanto a militancia no era "afecto a la ciencia media", falleció siendo oidor del mismo en 1781.

Analizada ya la trayectoria seguida por los miembros de las Audiencias y el consejo navarro, nos proponemos cotejar la progresión política de los miembros de las Chancillerías de Valladolid y Granada, teniendo en cuenta que mientras en la primera el número de jesuitas rondaba el $36 \%$, en la segunda la militancia en esta escuela era muy superior, con el $85 \%$. Para que resulte más gráfico comprobar cuál fue la meta final alcanzada por los magistrados que se hallaban sirviendo en ambas Chancillerías en 1765 hemos confeccionado un cuadro en el que, asimismo, presentamos el último empleo a que accedieron los alcaldes de Casa y Corte. 


\begin{tabular}{llllll}
\hline \hline $\begin{array}{l}\text { TRIBUNAL } \\
\text { DE ORIGEN }\end{array}$ & \multicolumn{5}{c}{ DESTINO FINAL } \\
\hline & $\begin{array}{l}\text { Consejo } \\
\text { Castilla }\end{array}$ & $\begin{array}{l}\text { Otros } \\
\text { Consejos }\end{array}$ & $\begin{array}{l}\text { Mismo } \\
\text { tribunal }\end{array}$ & Otros & Total \\
Granada & 8 & 5 & 11 & 2 & 26 \\
Valladolid & 7 & 3 & 14 & 3 & 27 \\
Casa y Corte & 7 & 4 & 2 & - & 13 \\
\hline \hline
\end{tabular}

Las cifras que nos proporciona el cuadro sobre los ascensos conseguidos por los magistrados de ambas Chancillerías son bastante próximas. si bien hay que hacer notar que detrás de esos números se esconden realidades bien distintas que intentaremos sacar a la luz recurriendo a un minucioso comentario.

De los ocho ministros de la Chancillería de Valladolid que llegaron a conseguir una plaza de consejero de Castilla dos habían sido calificados como "tomistas", el presidente Andrés Maraver y el oidor Gonzalo Enríquez; el primero logró dicho empleo en 1766, mientras el segundo tardó algo más de tiempo, ya que no accedió a él hasta 1773, después de pasar por la regencia de Galicia.

También José Faustino Pérez de Hita, el conde de Balazote, Andrés González Barcia, Antonio Inclán, Francisco Gabriel Herrán y Manuel Doz, pese a haber sido calificados conjuntamente como "jesuitas", lograron formar parte del más alto tribunal del Reino ${ }^{54}$. Maraver. Pérez de Hita y Balazote. además, accedieron a la Cámara de Castilla.

Tras ser propuesto en dos ocasiones para la regencia del consejo de Navarra. y en una para la sala de alcaldes de Casa y Corte, la regencia de Valencia y la de Canarias, Pérez de Hita fue designado para este último destino, empleo del que, sin embargo, dimitió "a causa del accidente de reiteración de sangre por la boca que experimentó en los años de 1742 y 1757, con motivo de haberse embarcado en el Puerto de Santa Maria para pasar a Cádiz, y después en Motril por sólo estar en la inmediación al mar ${ }^{15.5}$. Admitida su dimisión, unos meses más tarde, en noviembre de 1767, le era confiaada la regencia de Cataluña; esta vez sí tomó posesión del cargo, desempeñándolo hasta 1770 en que fue ascendido al Consejo para cubrir la vacante dejada por el marqués de Montenuevo. Seis años más tarde pasó a formar parte de la Cámara, falleciendo en 1781 . 
Pese a que los informes le calificaban como ministro "bastante hábil, de mucho juicio y prudencia, de amable genio y de muy sana intención", Sebastián Maria Alfaro y Ortega, conde de Balazote, necesitó de veintisëis consultas de la Cámara $^{50}$-todas ellas presentadas entre enero de 1765 y agosto de 1773- para cambiar su plaza de oidor en la Chancillería granadina por la de alcalde de Casa y Corte. Aunque tres años más tarde logró un asiento en el consejo de Castilla, y en la Cámara desde 1782, ser hijo de Pedro Juan Alfaro, consejero de Castilla desde 1736 y camarista desde 1748, y nieto del también consejero Sebastián Alfaro, no parece que fuera decisivo para que se le diera un tratamiento de favor.

Menores difícultades para ascender tuvo Andrés González Barcia, sobrino del consejero del mismo nombre, pues habiendo logrado ocupar plaza de oidor desde 1760, tres años después de que la obtuviera Balazote, entró como alcalde de Casa y Corte en 1767. Tras cumplir un trienio en este destino se le confirió una de las dos plazas togadas con que se incrementó el componente humano del consejo de Hacienda en $1770^{57}$. Unos años más tarde, adelantándose nuevamente a Balazote, González Barcia ascendió aí consejo de Castilla en octubre 1774; sin embargo, no llegó a saborear las mieles del preciado puesto de camarista, ya que falleció en 1779 .

También Antonio Inclán se adelantó a Balazote en la carrera de ascensos. Oidor de Granada desde 1761. obtuvo en octubre de 1769 un empleo de alcalde de Casa y Corte. tras ser consultado en cuatro ocasiones para esta plaza y en una para las regencias de Canarias, Cataluña, Aragón, Sevilla y Galicia. Trasladado a Madrid, apenas si permaneció un año en dicho destino, pues en octubre de 1770 era consultado y designado fiscal del consejo de Órdenes, de donde pasó, en abril de 1774, al de Castilla.

Otro ejemplo de retraso en la carrera es el de Francisco Gabriel Herrán, especialmente significativo si lo comparamos con la rápida progresión de Manuel Doz.

Alcalde del crimen desde 1761, Manuel Doz ascendió a oidor en enero de 1768; tres años más tarde, en octubre de 1771, pasaba a Madrid como alcalde de Casa y Corte; no llegó a completar un bienio en dicho tribunal, pues en julio de 1773 fue designado para la presidencia de Granada, de donde salió a principios de 1777 para incorporarse al consejo de Castilla.

Frente a esta fulgurante carrera, Francisco Gabriel Herrán, alcalde del crimen desde marzo de 1760 y oidor desde agosto de 1766 , tuvo que esperar más de veinte años para obtener plaza de alcalde de Casa y Corte en 1787, y otros cinco para la de consejero de Castilla, que no logró hasta junio de 1792. Pese a la buena opinión que había sobre sus conocimientos y conducta, Herrán fue postergado en los ascensos posiblemente por haber sido calificado como "jesuita". 
Como una muestra de su preparación y cualidades traemos a colación los informes presentados en 1787 por el presidente de la Chancillería de Granada y el obispo de esta misma ciudad; decía el primero que:

"es un magistrado de mucha integridad y desinterés, muy asistente a la Chancillería y activo en el desempeño de sus comisiones. Es buen letrado y de una instrucción nada común. porque sabe con esmero la geografia antigua y moderna; conoce la historia universal de Europa, y con especialidad la de España. Traduce con primor el griego en todos sus dialectos; entiende medianamente el inglés; habla el francés corriente, y no con poca propiedad; y se hace entender en italiano, pero es tanta su moderación y humildad que es menester gran confianza ofrecuente trato para manifestar su talento y conocimientos" ${ }^{158}$.

El obispo de Granada hizo hincapié, asimismo, en que era "en ciencia sobresaliente, sabio, de costumbres ejemplares, aplicación, celo y desinterés en sumo grado"ss.

Sólo el desconocimiento de semejantes cualidades podría explicar su atraso en la carrera; sin embargo, es imposible recurrir a este argumento para justificar dicho extremo, pues ya a comienzos de la década de los sesenta dijo de él el consejero de Castilla Francisco José de las Infantas que era:

"de muy buena literatura teória y práctica, experimentada ésta en el servicio de la asesoría de dicha universidad [Alcalá], en donde se ventilan litigios de todas especies, $y$ jurisprudencia civil $y$ canónica, y ha procedido en ellos con integridad, justificación y limpieza; que es de muy buenos talentos y comprensión, y en su porte, recogimiento $y$ conducta se ha reconocido regular $y$ arreglado ${ }^{160}$.

Además de las buenas cualidades que también Manuel Doz reunia, debió ser el aval familiar el que le hizo progresar tan rápidamente y adelantar a Herrán en la carrera de los estrados con bastantes años de diferencia. En 1760, año en que se incorporó Doz a la Chancillería granadina, apuntó el consejero Manuel Arredondo que era:

"de familia muy distinguida, emparentado con personas de mucho mérito y honor. Que tiene en dicha universidad [Huesca] y su colegio un concepto y crédito muy grande de su literatura y mérito, y ha servido por muchos años con la aplicación a la enseñanza pública, y en muchos encargos y comisiones en la práctica. a que 
se le juntan muchas buenas prendas de prudencia y buen trato con las gentes" ${ }^{16 !}$.

Pese a que las puertas del consejo de Castilla permanecieron cerradas para ellos, algunos magistrados del tribunal granadino lograron acceder a otros consejos como el de Órdenes, Hacienda e Inquisición.

Aunque su "literatura y habilidad" no fueran "sobresalientes", su "buen genio, juicio, porte y desinterés", así como los lazos sanguineos que le unían al que fuera oidor de la Chancillería de Valladolid, Rodolfo Arredondo -su padre-, y al consejero Manuel Arredondo -su hermano-, aceleraron el ascenso de Miguel Arredondo Carmona, que de oidor de Granada desde 1760 pasó en 1765 a ocupar la intendencia de Córdoba y de aquí, en 1767 , al consejo de Hacienda. Su carrera, sin embargo, se vio bruscamente interrumpida al fallecer en diciembre de 1769 cuando apenas contaba cincuenta años.

Bartolomé Bruna y Ahumada, hijo del consejero de Castilla Andres de Bruna, y sobrino del virrey de Nueva Espana marqués de las Amarillas, se incorporó, asimismo, al consejo de Hacienda en 1775.

Como hemos tenido ocasión de comprobar en ejemplos anteriores, también en las carreras de los dos individuos que acabaron sus días en el consejo de Órdenes existe un considerable desfase cronológico; José Severo Cuéllar y Gonzalo José Treviño obtuvieron sus plazas de oidores en 1763 y 1764, respectivamente, pero mientras el primero era ascendido a alcalde de Casa y Corte en 1769, y consejero de Órdenes en 1773, Gonzalo Treviño no consiguió promocionar hasta $1781^{\circ 2}$, momento en que se le confirió la regencia sevillana, de donde sería destinado al consejo de Órdenes en 1786 , el año de su muerte.

Por último, cabe reseñar que Felipe Santos Domínguez, el fĩscal granadino calificado de "tomista", tuvo una rápida carrera que le llevó en 1769 a obtener una plaza de alcalde de Casa y Corte, en 1773 al consejo de Indias y, tres años más tarde, a formar parte de la Cámara de Indias.

Analizada ya la trayectoria de los magistrados de la Chancillería de Granada que acabaron sus días en uno de los Consejos de la monarquía no nos queda sino comentar la de aquéllos que no salieron de dicho tribunal y la de los dos individuos que, pese a subir en el escalafón, quedaron como alcalde de Casa y Corte -en el caso de Luis Melgarejo- y regente de la Audiencia de Sevilla -marqués de los Llanos-.

Tanto José Olmeda y León, marqués de los Llanos, como Luis Melgarejo y Rojas, que en 1765 eran alcaldes del crimen en Granada, pasaron a oidores de dicho tribunal en 1767 y 1773, respectivamente. En 1776, y después de ser consultado para la presidencia de Valladolid, alcalde de Casa y Corte -en cuatro 
ocasiones- y regente de Sevilla -en dos- Olmeda fue designado para este último destino, en el que acabaría sus días en 1780. Luis Melgarejo, por su parte, pasó a Madrid como alcalde de Casa y Corte en 1786, en sustitución de Manuel Sisternes, no sin antes figurar en, al menos, seis consultas en las que se le proponía para esta misma plaza -dos veces-, para el consejo de Órdenes -tres- y la regencia de Cataluña; y contar con informes favorables del consejero Luis del Valle, del presidente de la Chancillería de Granada Jerónimo Velarde y otros importantes ministros.

Entre los magistrados que fallecieron sin salir de la ciudad del Darro figuran Francisco Ansoti, jubilado en 1776; el "tomista" José de la Portilla, muerto en 1767; Gonzalo Ulloa ( $\uparrow$ 1766), Francisco Crespo Aguero ( $\uparrow 1769)$, Gonzalo Rioja ( $\uparrow 1771)$, Pablo Antonio Ramos ( $\uparrow 1774)$, Vicente Olmedilla ( $\uparrow 1778)$, Pedro Davila ( $\uparrow 1778)$, José Pineda y Tavares $(\uparrow 1786)$, Francisco Alfonso Quevedo y Diego Bernardo Oruña. En los sujetos que fallecieron a finales de la década de los sesenta o primeros años de los setenta puede haber dudas sobre el origen de la falta de promoción; sin embargo, en los que rebasaron estas fechas el factor jesuita u otros tan poco recomendables como aquél debieron ser los responsables de que dichos ministros quedaran anclados en su destino granadino; sólo traeremos a colación dos ejemplos, el de Francisco Ansoti y el de Vicente Olmedilla.

Juan Francisco Ansoti, que desde 1736 ejercía como oidor en Granada fue jubilado en 1776 sin haber experimentado ascenso alguno. Aunque era "ministro docto, ingenioso, aplicado, sagaz, primoroso en explicarse de palabra y por escrito", no podemos achacar exclusivamente a su militancia "jesuita" la falta de promoción: de hecho debió venir más condicionada por estar "notado de codicioso y de haber recibido regalos de aigunos litigantes, asi en especie como en dinero", como por ser "de genio altivo y algo vengativo" ${ }^{163}$.

Si en el caso de Ansoti la ausencia de ascensos pudo estar motivada por su interesada conducta, en el de Vicente Olmedilla todo hace pensar en el factor jesuita, pues pese a ser calificado por el presidente de la Chancillería granadina como "de gran rectitud y justificación, generalmente estimado por su bondad y genio, y de regular literatura y buena comprensión, aunque de poco lucimiento" ${ }^{164}$, y ser consultado en trece ocasiones para diferentes empleos, no obtuvo ninguno de ellos ${ }^{65}$.

Si en el escrito del anónimo informante de Roda se echaba en falta un juicio personalizado sobre las inclinaciones de los ministros de la Chancillería de Granada, en la de Valladolid, afortunadamente, aquéllos existen y, siempre que la longevidad del individuo lo permite, posibilitan el seguimiento de los ascensos en función de la militancia.

Contrariamente a lo que cabría esperar, sólo tres de los siete individuos que terminaron sus días en el consejo de Castilla habían sido definidos como tomistas ${ }^{66}$. Aunque en números absolutos esta cifra pueda parecer baja, lo cierto es que, en 
términos porcentuales, representa algo más del $21 \%$ de quienes fueron distinguidos con dicho calificativo; si además tenemos en cuenta que el $57 \%$ de ese colectivo murió antes de 1780 se entiende mejor que no lograran llegar a la cima de la pirámide de ascensos ${ }^{67}$.

El presidente del tribunal vallisoletano, Vicente Valcárcel y Formento, marques de Pejas, un "sujeto de avanzada edad, inclinación práctica a los jesuitas, literato y laborioso, pero adherido a su dictamen y pagado de su autoridad", entró a formar parte del consejo de Castilla a partir de 1767, permaneciendo en él hasta su muerte, ocurrida en 1772 .

Aunque siguiendo el orden natural de ascensos ${ }^{\text {is }}$-cronológico- debiera haber sido Manuel Fernández Vallejo el siguiente en incorporarse al consejo de Castilla, le precedió José Vitoria; también José Manuel de Herrera y Navia se le adelantó.

José Nicolás de Vitoria y Landeche, jesuita de "mediano concepto, pero ardiente y pagado de su dictamen", fue destinado en junio de 1768 a la regencia aragonesa; algo menos de tres años después, y tras figurar su nombre en siete ternas dirigidas a cubrir plazas del consejo de Castilla, entró a formar parte del mismo.

Herrera y Navia, un leonés calificado de "tomista, mediano concepto, estudioso, pero nimio en impertinencias", aunque de honestas costumbres, obtuvo la regencia de Mallorca a finales de 1770 , empleo en el que permaneció hasta marzo de 1773 en que pasó como regente al consejo de Navarra. Con la experiencia adquirida al frente de ambos tribunales, Herrera fue consultado repetidamente para plazas del consejo de Castilla a lo largo de 1775 -cinco veces-, logrando la designación a finales de ese año.

El retraso experimentado en la carrera por Fernández Vallejo se debió, sin duda, a ser calificado de "projesuita"; dicha lacra le supuso ser consultado en catorce ocasiones antes de conseguir una plaza de alicalde de Casa y Corte ${ }^{04}$, cargo que obtuvo en el verano de 1772. De nuevo transcurrieron siete años, y repetidas consultas, antes de que Manuel Fernández llegara al consejo de Castilla, su último destino.

Francisco García de la Cruz y Obregón, "tomista, estudioso", pero con corto concepto de letrado, ocupaba en 1765 una de las alcaldías del crimen, empleo que dejó en 1767 tras ser ascendido a oidor. Corregidor de Guipúzcoa desde 1774, se incorporó cuatro años después a la sala de alcaldes de Casa y Corte, donde permaneció por espacio de diez años hasta que en julio de 1784 fue nombrado consejero de Órdenes; de allí pasó, a los cinco años, al de Castilla en la vacante ocurrida por fallecimiento de Blas de Hinojosa. 
La calificación aplicada a Andrés Bruno Cornejo era la de ser "indiferente en la adhesión a religiones, corto concepto en lo literato, muy nimio y escrupuloso, $y$ de honesta vida"; consecuente a la definición hecha de él, Cornejo, que desde 1758 ocupaba plaza de alcalde de hijosdalgo, no ascendió a oidor hasta 1771. El carácter introvertido del referido ministro llevó al presidente de la Chancillería a emitir un informe sobre él, en términos parecidos, en octubre de 1774 en el que lo caracterizaba como:

\begin{abstract}
"muy aplicado, íntegro, modesto, virtuoso, puntual al tribunal y deseoso del acierto, para lo que no perdona medio ni diligencia; su comprensión y literatura sería más que razonable para los pleitos ordinarios a no tener genio encogido y estudio privado sin método y guia, y que siempre se halla con timidez por no poseer las cosas con firmeza y claridad, y es de parecer que con el ejercicio y práctica de negocios se venza"70.
\end{abstract}

En junio de 1777 fue designado alcalde de Casa y Corte, y nueve años más tarde, en abril de 1786, tras figurar su nombre en cuatro ternas, pasó a integrarse en el consejo de Castilla, empleo del que se jubiló en 1796.

El último de los magistrados vallisoletanos en incorporarse al más alto tribunal del Reino fue Juan Miranda y Oquendo. Miembro de una familia originaria de Ciudad Rodrigo, y con experiencia en el campo de la administración ${ }^{7 !}$, Juan de Miranda, fiscal de la Chancillería de Valladolid desde 1748, ingresó en octubre de 1767 como consejero de Castilla. Las palabras del anónimo informante de Roda, que lo definían como "tomista, excelente ingenio, hombre muy práctico, aunque notado de no asociarse con los demás ministros", debieron ser concluyentes para tan meteórico ascenso.

Contrariamente a lo sucedido en el tribunal granadino, donde tres de los magistrados existentes en 1765 llegaron con el tiempo a formar parte de la Cámara de Castilla, en el de Valladolid ninguno ocupó tan relevante puesto.

Entre los individuos que lograron plaza en algún otro de los consejos establecidos en la Corte figuran los tomistas Benito Barreda y Pedro Calderón, así como el jesuita José de Lardizábal.

Pese a ser "poco letrado y lleno de vanidad", y tratar con desprecio al personal, Benito Barreda y Yebra, por el hecho de ser un "antijesuita grande", fue ascendido en septiembre de 1766 a alcalde de Casa y Corte. Aunque propuesto en los años siguientes en seis ocasiones para el consejo de Castilla y en dos para el de Órdenes, no fue hasta junio de 1771 cuando logró una plaza en este último tribunal, destino en el que falleció en 1784. 
También Pedro Calderón Enríquez debió a su militancia tomista su ascenso a consejero en 1766, en este caso el de Indias, tras llevar únicamente dos años como oidor del tribunal vallisoletano ${ }^{72}$.

José de Lardizábal, pese a tener prácticamente la misma antigüedad en el cargo que Barreda -ambos habían sido ascendidos a oidor en 1760-, así como "mediano concepto en io letrado, y sin nota en su proceder", por su condición de "jesuita" hubo de esperar hasta 1771 para lograr otro empleo, en este caso como regente de la Audiencia de Cataluña. Tres años más tarde obtenía un nuevo ascenso al ser designado para el consejo de Hacienda, en cuyo ejercicio falleció en 1776.

Los magistrados que, pese a ser destinados a otros tribunales, no llegaron a conseguir un puesto en cualquiera de los consejos fueron Francisco Salazar, Manuel Garcia Alesón y Felipe Díez, todos ellos tomistas.

Francisco. Salazar y Bustamante, un "letrado estudioso y aplicado al despacho, aunque nimio e impertinente en las réplicas que hace para instruirse", fue designado alcalde de Casa y Corte en marzo de 1767, pocos meses antes de fallecer. Ese mismo año murió también Manuel García Alesón, ascendido en agosto del año anterior a fiscal del mismo tribunal madrileño.

Notablemente distinto a los dos casos anteriores -en los que la falta de promoción se debió al fatídico desenlace- fue el de Felipe Díez de Quijada. Alcalde del crimen desde 1762, no obtuvo plaza de oidor hasta 1771, permaneciendo en ella por espacio de diez años, pese a ser repetidamente consultado para alcalde de Casa y Corte -en cinco ocasiones- y regente de las Audiencias de Mallorca, Cataluña y Galicia.

Diez Quijada era, según el anómino informante de Roda, un tomista de "corto concepto", aunque de vida honesta. En octubre de 1774 Raimundo Irabien, presidente de la Chancillería de Valladolid desde hacia unos meses, lo definia como:

"de puntual asistencia, robusto, genio fuerte, corta expresión, que muchas veces toca en grosería; indócil y ambicioso de disponerlo y domiciliarlo todo; no es aficionado ni dichoso en la lectura, aun en las reglas triviales de la jurisprudencia tiene sus tropiezos y equivocaciones, y suele prevenir en los pleitos por conexiones" ${ }^{173}$.

Unos años más tarde, a comienzos de la década de los ochenta, el nuevo presidente vallisoletano, Gregorio Portero, se reafirmaba en dicho juicio al señalar que:

"carece de toda instrucción; es corto criminalista y cortisimo civilista (...); es fácil a los empeños y recomendaciones, y duro a entender, cuando median éstas, la razón y la justicia" ${ }^{74}$. 
No era sólo su conducta en los tribunales lo que censuraba Portero, ya que, según apuntó mas adelante, Díez de Quijada tenia importantes valedores entre los colegiales:

"Sé que le protejen el Sr. Gálvez, de quien es condiscípulo de Filosofia, el Sr. gobernador del Consejo, D. Domingo Alejandro Cerezo, la casa del marqués del Campo de Villar y todos los aliados de ella" ${ }^{17}$.

Las continuas filtraciones existentes en el tribunal vallisoletano hicieron aconsejable que la opinión del presidente fuera transmitida a Roda con carácter secreto pues, según apuntó Gregorio Portero, "aqui nada se ignora de los informes de oficio, quedando uno expuesto, por la verdad, al embate y persecución de todas estas gentes (hablo de todo el colegialismo)". Unas semanas después de la primera carta remitió otra en la que aludia al carácter mujeriego de Quijada ${ }^{76}$.

Aunque calificado en 1765 de tomista, a comienzos de la década de los ochenta se le incluía en el grupo opuesto, por lo que esta razón, o todas las carencias que hemos ido comentado detenidamente, pudieron influir en el retraso que experimentó su carrera, ya que no consiguio ascender hasta 1781 , momento en que, se le confió la regencia de Galicia, empleo en cuyo ejercicio falleció once años más tarde.

De los catorce magistrados que acabaron sus días en ei mismo destino -o al menos en el mismo tribunal- en que se hallaban en 1765 , seis habian sido definidos como tomistas $^{75}$, otros tantos como jesuitas ${ }^{78}$, mientras sólo dos fueron calificados como imparciales o indiferentes "en la inclinación de religiones ${ }^{179}$. Aunque en algún caso pudo ser el pronto fallecimiento el que privó a dichos ministros de un ascenso, pensamos que la falta de promoción de los tomistas fue debida básicamente a su escasa preparación jurídica, que aconsejó evitar su paso a puestos de mayor responsabilidad; como botón de muestra nos limitaremos a presentar dos ejemplos.

José Verdes Montenegro, un tomista a quien el anónimo informante de Roda calificaba como "de escaso concepto en lo literato", fue definido por el presidente de la Chancillería de Valladolid, en octubre de 1774, como de "escasa literatura, ninguna experiencia en los negocios, grande falta en los principios de la profesión y absoluta ignorancia del orden ritual de los procesos" ${ }^{180}$. Un sexenio más tarde Gregorio Portero coincidia nuevamente en la valoración al indicar que era "muy corto $y$ sin instrucción ${ }^{181}$.

Juan Domingo Junco, por su parte, fue calificado en 1765 como de "muy limitada literatura y poca resolución", mientras quince años más tarde apuntaba Gregorio Portero que era "muy corto en su oficio, muy engreido; no tiene estudio alguno a excepción de las obras de S. Francisco de Sales" ${ }^{\prime 82}$. 
Por último, no nos queda sino comentar la posterior trayectoria de los individuos que en 1765 compartían un puesto en la sala de alcaldes de Casa y Corte. La estrecha relación existente entre este tribunal y el consejo de Castilla ${ }^{83}$ hizo que la mayor parte de los individuos que obtuvieron una plaza en el primero acabaran sus días en el segundo, o en alguno de los otros consejos, independientemente de las inclinaciones que hubieran manifestado. Sólo el pronto fallecimiento de Manuel Domingo Sánchez Salvador, ocurrido en 1767, y la escasa salud de Antonio Sesma impidieron que éstos lograran un empleo semejante al conseguido por sus compañeros $^{84}$.

Encontraron un puesto en el consejo de Castilla Nicolás Andrés Blasco, designado en septiembre de 1765 y fallecido un año más tarde; Manuel de Azpilicueta, quien tras cuatro años como fiscal del consejo de Órdenes fue ascendido en 1770 al de Castilla para cubrir la vacante dejada por el marqués de Montenuevo: y Manuel Ramos Crespo, un "jesuita profeso" que se incorporó en julio de 1769 para sustituir a Juan Antonio Curiel, recientemente jubilado.

También Agustín Leiza y Eraso, un jesuita de cuarto voto que era hijo del que fuera consejero de Castilla José de Leiza, completó la carrera de ascensos al ser designado consejero de Hacienda en enero de 1767, del de Castilla a partir de noviembre del mismo año, y camarista por decreto de 29 de junio de $1770^{85}$.

Fernando José Velasco Cevallos, fiscal de la sala de Alcaldes de Casa y Corte en 1765, fue el magistrado expresamente descalificado por el informante de Roda para ocupar la presidencia de cualesquiera de las Chancillerías peninsulares; pues bien, apenas un año más tarde se le concedía la de Granada ${ }^{86}$, empleo que desempeñó hasta que en febrero de 1770 se incorporó al consejo de Castilla en la vacante dejada por Simón de Anda y Salazar. Unos meses más tarde, en julio del mismo año, le era confiada una plaza en el consejo de la Inquisición y, finalmente, en octubre de 1785 , se incorporaba como camarista ${ }^{87}$.

Como los anteriores, también ocuparon plaza en el más importante tribunal del Reino los tomistas Felipe Codallos, consejero de Hacienda desde 1766 y de Castilla desde septiembre del año siguiente; y Pedro Avila y Soto, consejero de Indias desde 1767 y ascendido al de Castilla en 1768.

Juan Moreno Beltrán, un jesuita de cuarto voto que, como dejamos dicho anteriormente, contó con el patrocinio del gobernador del Consejo, murió siendo consejero de Órdenes en 1769. Para sustituirle fue designado Juan Esteban Salaverri, quien pese a ser consultado en cuatro ocasiones entre 1767 y 1768 para cubrir sendas plazas en el de Castilla, y otras ocho entre 1772 y 1774 no logró la designación, acabando sus días al frente del de Órdenes ${ }^{88}$. 
Ser un jesuita profeso tampoco fue óbice para que José Güell y Serra fuera elevado al consejo de Hacienda en 1767; sin embargo, no logró plaza numeraria en el de Castilla, aunque sí obtuvo los "honores, antiguedady sueldo" a partir de $1789^{84}$.

Por último recogemos el caso de José Gálvez ${ }^{\circ 0}$, el alcalde de Casa y Corte que mayor protagonismo político adquirió, ya que de dicho tribunal pasó a formar parte del Consejo y Cámara de Indias y, posteriormente, tras participar activamente en la expulsión de los jesuitas del virreinato de Nueva España, ocupó la Secretaría de Estado y del Despacho de Indias a partir de 1776 hasta su fallecimiento en $1787^{\circ}$.

El elevado número de ejemplos analizados nos permite concluir que la valoración expresada en el informe dirigido a Roda en 1765 sobre la militancia de los miembros de los tribunales hispanos tuvo gran importancia en la posterior evolución de su carrera administrativa, aunque no resultó concluyente. Otras consideraciones como la preparación jurídica del individuo, los empleos desempeñados por algunos de sus ascendientes más directos, etc. fueron asimismo sopesadas a la hora de aprobar un posible ascenso. Contar con apoyos familiares o de otros personajes ilustres pudo hacer olvidar, o al menos mitigar, la trascendencia de un juicio inculpatorio; en el extremo opuesto, una conducta licenciosa o la ineficacia reiterada en los tribunales eclipsó, en ocasiones, el epíteto de tomista o antijesuita que algunos lucieron junto a sus nombres. 


\section{NOTAS}

1.- OLAECHEA, R., "El anticolegialismo del gobierno de Carlos III", en Cuadernos de investigación. Geografia e Historia, tomo II, fasc. 2 (Logroño, 1976), pp. 53-90.

2.- A.C.S. Gracia y Justicia. Leg. 590. Noticia de los ministros que componen el Consejo supremo de S.M. y de otros dentro y fuera de esta Corte.

3.- OLAECHEA, R., "El anticolegialismo...", p. 55.

4.- José Aparicio Ordónez, Andrès de Valcárcel Dato, y el conde de Troncoso eran calificados de jesuitas; Juan Martín de Gamio, por su parte, era sospechoso de mantener identica postura.

5.- Diego de Rojas y Contreras, Juan Curiel, Francisco José de Cepeda, Simón de Baños, Francisco de la Mata Linares, José Moreno y Lope de Sierra y Cienfuegos.

6.- A.G.S. Gracia y Justicia. Leg. 590. Noticia de los Ministros...

7.- Cristóbal Monsoriu, Pedro de Castilla Caballero, Miguel Maria de Nava, Pedro Ric y Fjea, y Luis del Valle Salazar eran definidos como tomistas.

8.- Aunque por regla general se tendio a incluir a los colegiales entre los seguidores de la Compañía de Jesus, esta correspondencia no siempre fue exacta, existiendo honrosas excepciones como la de francisco Saiazar, colegial de Santa Cruz de Valladolid, o Francisco Foich de Cardona y Felipe Diez de Quijada, colegiajes de San Ildefonso, todos ellos destacados tomistas. Sobre la vinculación de ios colegiales con la Compañia vid. OLAECHEA, R., Op. cit., p. 64 y sígs.

9.- En el consejo de Indias eran todos sus miembros jesuitas a excepeión del marqués de Valdelirios, Pedro de León y Escandón, José Banfi y Parrilla, Marcos Jimeno, Domingo Tres-Palacios y los dos fiscales.

10.- En el consejo de Órdenes sólo habian dudas sobre Gómez Gutiérrez de Tardoya, siendo el resto "profesos jesuitas".

11.- En el consejo de Hacienda sólo Julian de Hermosilla y el marques de San Juan de Tasso eran "seguros tomistas".

12.- El anónimo informante decia que el consejo de Inquisición habia "mejorado mucho, pues excepluando ei inquisidor general y D. Felipe Muñoz, que son jesuitas profesos, lo demás está bien".

13.- Los individuos calificados como jesuitas eran Francisco de la Mata Linares, José Güell y Serra, Manuel de Azpilcueta, José Moreno Beltrán, Manuel Ramos, Agustín de Leiza y Eraso, Nicolás Blasco y Fernando José de Velasco.

14.- En este grupo quedaban englobados Antonio de Sesma, Felipe Codallos, Juan Esteban Salaberri, Pedro Davila y Soto, José Gálvez Gallardo y Manuel Domingo Sánchez Salvador.

15.- En la Chancillería de Granada únicamente el presidente Andrés Maraver, los oidores Gonzalo Enríquez y José de la Portilla, y el fiscal Felipe Santos Dominguez eran considerados tomistas.

16.- Era cl caso de Santiago Rico Palmero, Andres Cornejo y Pedro Chaves. 
17.- Respecto a los magistrados de la Audiencia gallega se decia que todos eran jesuitas, salvo Luis Jiménez de Saboya, Fernando de Castro Jimeno y el fiscal José Antonio Giraldo.

18.- En la Audiencia de Oviedo el único magistrado calificado como antijesuta era Cristobal Vivero Sánchez Calderón, si bien tampoco Pedro González de Mena habia mostrado especial "adhesion a ios jesuitas".

19.- Un $73,3 \%$ de los ministros valencianos era calificado como jesuita, mientras el $26,6 \%$ restante tra definido como tomistas.

20.- La Audiencia mallorquina, según el anónimo informante, estaba ocupadia enteramente por jesuitas.

21.- En el consejo de Navarra el regente, José Contreras, aunque procuraba mostrar indiferencia, era más inclinado a "tomistas que a jesuitas"; entre los restantes ministros también estaban estos últimos en minoria, pues frente a un $36.36 \%$ de seguidores de la Compañia, habia un $63.63 \%$ de individuos que eran afectos a Santo Domingo, Santo Tomas, o el Carmen, que eran enemigos de la Ciencia Media, o bien no militaban en ninguna de las dos principales escuelas.

22- A.G.S. Gracia y Justicia. Leg. 165, y Lib. 1.574. A.H.N. Consejos. Lib. 738. Gacera de Madrid, 26 de junio de 1770 .

23.- Moreno Alvarado fue definido como tomista, mientras Muñoz lo fue de jesuita.

24.- Marcos Jimeno informó que José Moreno "ha comprado hacienda raiz en este reino que le renta 1.500 pesos, vendiendo, según se asegura, la suya en su pais"; otro tanto había hecho Muñoz, quien "se ha hacendado en este reino y ciudad, en lo que tiene puesto su principal cuidado", en A.G.S. Gracia y Justicia. Leg. 590. Informe sobre los miembros de la Audiencia de Valencia (1760).

25.- A.G.S. Gracia y Justicia. Leg. 160. Juan José de Eulate al conde de Aranda, 29 de febrero de 1772.

20.- Castro tue consultado en tercer lugar por los meses de febrero y marzo, en primero en mayo y junio. y en segundo el 12 de septiembre, sin lograr la designación regia.

27.- MOLAS RIBALTA, P., "Magistrats de l'Audiència borbonica"; en Mayurqa 22 (1989), p. 829.

28.- A.G.S. Gracia y Justicia. Leg. 160. La Cámara. 14 de marzo de 1770, propone para ia presidencia de la Chancilleria de Granacia.

29.- En febrero de 177. Caro fue consultado para la presidencia de la Chancilleria de Valladolid -ya to habia estado en 1770 para la de Granada-, empleo que no obtuvo, como tampoco el de consejero de Castilla pese a figurar en cuatro ternas presentadas a lo largo de 1772 y 1773.

30.- Gacera de Madrid. 21 de junio de 1774.

31.- Sólo Gaspar Cebriản y Sebastián Castillo, fallecidos en 1765 y 1760 , respectivamente, no promocionaron a empleos superiores.

32.- Pedro Ignaio Llanzol y Miguel Jurado tallecieron en 1766 , mientras Bernardo Torrijos lo hacia un año más tarde.

33.- Aunque José Maria Reina fue repetidamente propuesto por la Cámara para plaza de alcalde de Casa y Corte en los años 1771, 1772, 1773, 1777 y 1779, no logró ser designado. Cfr. A.G.S. Gracia y Justicia. Leg. 161 y 162 . 
34. - De hecho la faita de una promoción significativa fue habituai, ya que en la práctica ei tribunal balear funcionó en todo momento como "una Audiència d'entrada des de la qual no s'assolien ascensos importants". Cfr. MOLAS RIBALTA. P., Op. cit., p. 831.

35.- A.G.S. Gracia y Justicia. Leg. 154. La Cámara, 21 de octubre de 1754, propone para una plaza de oidor de la Chancillería de Granada; y Leg. 590. José Manuel de Villena al marqués del Campo de Viliar, 1760 .

36.- José Manuel de Villena apuntó que "las adherencias que ha contraído con su larga residencia, y acomodo de sus hijos, le mueven en ocasiones y es causa de que se apasione"; por su parte, Sánchez Salvador afirmo que "al tener mucha familia, y casada alli, tiene muchas conexiones, por lo que esto es un serio obstáculo para la recta administración de la justicia", en A.G.S. Gracia y Justicia. Leg. 590. José Manuel de Villena ai marqués de Campo Viliar. La Coruña, 2 de enero de 1753 ; y Antonio Sánchez Salvador al marqués de Campo Villar, 19 de enero de 1760.

37.- Manuel Hermida y Porras falleció en 1766, Fernando Felipe de Castro y Jimeno en 1767, Jerónimo Romero en 1769 y Pedro de la Puente en 1773; de éstos Castro era el único que no habia sido calificado como jesuita.

38.- Portero de Huerta fue consultado para alcalde de Casa y Corte en 1771 y. dos veces, en 1773.

39.- A.G.S. Gracia y Justicia. Leg. 161. El marqués de Grimaldi a Manuel de Roda. San Ildefonso, 3 de septiembre de 1773 .

40.- Aunque ya en 1778 figuró su nombre en dos consultas presentadas para cubrir sendas plazas en ei consejo de Castilla, no fue hasta ia década de los ochenta, y tras ocupar la presidencia de Valladolid, cuando logró acceder al más alto tribunal de la monarquia.

41.- Velarde fue propuesto en tercer lugar, en julio de 1766 , para la fiscalía de la sala de $A$ icaldes de Casa y Corte; en septiembre lo fue en segundo para oidor de la Chancilleria de Valladolid y, de nuevo, en octubre, esta vez encabezando la terna, para un puesto similar en este mismo tribunal. Cfr. A.G.S. Gracia y. Justicia. Leg. 159 .

42.- Dos años después de incorporarse a la Chancillería vallisoletana, Jerónimo Velarde fuc propuesto para una plaza del consejo de Órdenes. En años sucesivos. y previamente a su designación para la regencia mallorquina, tue propuesto, asimismo, para las de la Audiencia de Aragón y el consejo de Navarra en 1771 y 1773 , respectivamente.

43. En 1759 Velarde fue definido como "adornado de un cabal conjunto de prendas de hiteratura, genio y costumbres ejempiares, porte poítico y las demás que bastan para formar un ministro completo", en A.G.S. Gracia y Justicia. Leg. 590. Joaquin Navarro ai marqués del Campo de Villar. Unos años mas tarde el consejero Juan Martin de Gamio io calificaba como "sujeto de talento, acompañado de aprovechamiento y de porte". en A.G.S. Gracia y justicia. Leg. 158. La Cámara, 20 de marzo de 1762. propone para una plaza de alcalde del crimen de la Chancilleria de Valladolid.

44.- El anónimo informante dijo de él que era "ministro docto y miy justificado, y hay alguna razón de congruencia para lenerle por jesuita".

45.- A lo largo de 1770 Fernández Villegas fue repetidamente consultado -en cuatro ocasiones- para sendas plazas del consejo de Castilla, siendo finalmente designado para cubrir la vacante por fallecimiento de Pedro León.

46.- A.G.S. Gracia y Justicia. Leg. 159. La Cámara, 3 de septiembre de 1766, propone para ana piaza 
47.- Taranco fue propuesto en cuatro ocasiones para plazas de alcalde de Casa y Conte -entre 1767 y 1769 y una para la regencia de la Audiencia de Galicia en diciembre de 1768.

48.- Aunque González de Mena fue propuesto en cuatro ocasiones en primer lugar para plaza de consejero de Castilla en los años 1769 y 1770 , fue repetidamente ignorado por el monarca, no alcanzado sino la fiscalia la primera vez que fue consultado para este empleo. La designacion de este ministro para las tareas fiscales debió estar condicionada por su experiencia en dicho empleo, ya que con anterioridad había sido abogado tiscal del tribunal de la Inquisición, fiscal de la renta del tabaco en Valladolid y fiscal del consejo de Indias.

49.- En 1762 el consejero Lope de Sierra lo calificaba como sujeto de "conocida habilidad aplicado y bien tmpuesto en su facultad: que a esto corresponde su buen juicio y la conducta que ha tenido en la universidad y su colegio, en que tiene mucha antigüedad, y estuviera ya catedratico a no haherse suspendido la provisión de cinco catedras vacantes con motivo de cierto recurso pendiente, que evacuado le corresponde ser catedrático en una de ellas". en A.G.S. Gracia y. Justicia. Leg. 158. La Cámara, It de julio de 1762, propone para una plaza de ministro de la Audiencia de Asnurias. Veinticinco años mas tarde el oidor de la Chancillería de Valladolid Fernando de Rojas corroboraba las buenas prendas de Vivero al indicar que "ha servido con celo, desinterés y continua asistencia, y le contemplo digno de que S.M. Ie atienda en plaza de Corte". También el obispo de Valladolid reconocia que era "muy pridente. de sana intencion y justo". El presidente de la Chancillería vallisoletana, por su parte, constataba que "ha desempeñado su obligación con inteligencia, justificación y tesón", si bien en los últimos años "ha ido y ra conocidamente decayendo de potencia y quebrantándose sucesivamente su rohustez y salud, de modo que su concurrencia al tribunal es una continua alternativa, especialmente en los inviernos". Estos tres ultimos juicios en A.G.S. Gracia y Justicia. Leg. 822. Fernando de Rojas al conde de Floridablanca. Valladolid, 22 de mayo de 1787; Manuel Joaquin, obispo de Valladolid. al conde de Floridablanca. Valladolid. 4 de junio de 1787; y Juan Matias de Azcárate al conde de Floridablanca. Valladolid. 28 de julio de 1787. Unicamente en el informe presentado por el presidente de la Chancillería de Valladolid. Gregorio Portero, en 1780 se perciben algunos defectos, pues to calificaba como "reguiar y aplicado, aninque bastante material; no tiene instrucción aiguna; es de buena indole y recogido; es de buenas costumbres y asistente al tribunal", en A.G.S. Gracia y Justicia. Leg. 162. Informe de Gregorio Portero. Valladolid, 16 de noviembre de 1780 .

50.- Juan Ascensio de Ezterripa figuró en una docena de consultas entre 1767 y 1774 , siendo propuesto en cinco ocasiones para una plaza de alcalde de Casa y Corte, dos para la regencia de la Audiencia de Mallorca, y una para las de Canarias, Sevilla, Galicia, Asturias y consejo de Navarra.

51.- Azcona falleció en 1776 siendo oidor del consejo navarro.

52.- SESE ALEGRE, J.M., El Consejo real de Navarra en el siglo XVIII. Pamplona, 1994, p. 217.

53.- Probablemente en Navarra, como en Mallorca, los "ministros nacionales" preferian acabar sus dias al frente del tribunal, evitando asi tener que abandonar su lugar de origen. Cfr. MOLAS RIBAL.TA. P., Op. cit., p. 826.

54.- Sobre el origen geográfico, formación universitaria, relaciones familiares, etc. de estos individuos vid. FAYARD, J., "Los ministros del Consejo Real de Castilla (1746-1788)", en Cuadernos de Investigacion Histórica n० 6 (1982), pp. 109-136.

55.- A.G.S. Gracia y Justicia. Leg. 159. La Cámara, 31 de octwbre de 1767 , propone para la regencia de la Audiencia de Cataluña. 
56.- Fue consultado en catorce ocasiones para el tribunal madrileño -once como alcalde de Casa y Corte y tres como fiscal de la sala-, nueve para plaza del consejo de Órdenes y una para las regencias de Sevilla, Galicia y Navarra

57.- A.H.N. Consejos. Lib. 738.

58.- A.G.S. Gracia y Justicia. Leg. 822. Juan Mariño al conde de Floridablanca. Granada, 6 de marzo de 1787 .

59.- A.G.S. Gracia y Justicia. Leg. 822. Informe del obispo de Granada. Granada, 26 de marzo de 1787.

60.- A.G.S. Gracia y Justicia. Leg. 157. La Camara, 4 de jebrero de 1760, propone para una plaza de alcalde del crimen de la Chancilleria de Granada.

61.- A.G.S. Gracia y Justicia. Leg. 157. La Cámara, 8 de noviembre de 1760, propone para una plaza de alcalde del crimen de la Chancilleria de Granada, con medio sueldo.

62.- Hasta conseguir el destino sevillano Trevino fue consultado en dieciocho ocasiones: doce para plaza de alcalde de Casa y Cone, cuatro para regente, y dos para el consejo de Ordenes.

63.- A.G.S. Gracia y Justicia. Leg. 590. Francisco de Cascajares al marqués de Campo Villar, 1752.

64.- A.G.S. Gracia y Justicia. Leg. 160. La Cámara, 28 de mar=o de 1770, propone para la regencia de la Audiencia de Asturias.

65.- Entre 1770 y 1777 Olmedilla fue consultado en cinco ocasiones para alcalde de Casa y Corte, asi como para las regencias de todas las audiencias peninsulares, la de Canarias y el conscjo de Navarra.

66.- Se trataba de Jose Manuel Herrera, Franeisco Garcia de la Cruz y Juan de Miranda.

67.- En 1767 fallecieron Francisco Salazar y Manuel Garcia Alesón, en 1769 José Ignacio Pizarro, en 1773 José Joaquín Arredondo, etc.

68.- Fernández Vallejo era oidor en Valladolid desde 1760 . Vitoria desde 1761 y Herrera desde 1764.

69.- Manuel Fernảndez fue repetidamente consultado para alcalde de Casa y Corte, consejero de Órdenes, presidente de la Chancillería de Granada y regente de casi todas las Audiencias.

70-- A.G.S. Gracia y justicia. Leg. 161. La Cámara 3 de junio de 1776.

71.- Su padre fue regidor de Ciudad Rodrigo y su hermano Luis alcalde del crimen y oidor de la Audicncia de Valencia, en cuyo destino falleció en 1742.

72.- Calderón fue calificado como "tomista, mediano concepto, imparcial, aunque muy achacoso por su larga edad".

73.- A.G.S. Gracia y Justicia. Leg. 161. La Cámara, 19 de diciembre de 1774.

74.- A.G.S. Gracia y Justicia. Leg. 162. Gregorio Portero a Mamuel de Roda. Valladolid, I de enero de 1780 .

75.- Ibídem. 
70.- Decía Portero que "este ministro ha estado reputado anteriormente por bastante lascivo y galanteador, con poca reserva. muy complaciente a estas amistades y notado en casos particulares i...). pero la edad y, io que es más seguro. el matrimonio le han corregido de modo que su vida es de su casa al tribunal", en A.G.S. Gracia y Justicia. Leg. 162. Gregorio Portero a Ntamel de Roda. Valladolid. 25 de enero de 1780.

77.- José Ignacio Pizarro, Juan Domingo Junco Larrumbide, Francisco Javier Foich de Cardona. José Joaquin Arredondo, Jacinto Bretón y José Verdes Montenegro.

78.- Francisco Villarreal, Fernando Rojas, Manuel Joaquín Saicedo, Manuel Gómez de la Torre, Pedro Manuel Martinez Feijoo y Manuel Juan de Cereceda.

79.- Estos dos magistrados eran Santiago Rico Palmero y Pedro Chaves Villarroel.

80.- A.G.S. Gracia y Justicia. Leg. 161. La Cámara, 19 de diciembre de 1774.

81.- A.G.S. Gracia y Justicia. Leg. 162. Informe de Gregorio Portero. Valladolid. 16 de noviembre de 1780.

82.- Ibidem.

83.- FAYARD. J.. L.os miembros del Consejo de Castilla (162l-1746). Madrid, 1982, p. 22.

84.- De Sesma decia el anonimo informante de Roda que "no es jesuita, pero está imposibilitado por su faita de salud, y pierde el rey un grande y justificado ministro". Cfr. A.G.S. Gracia y Justicia. Leg. 590. Noticia de los ministros...

85.- Cfr. Gaceta de Madrid, 27 de enero de 1767, 1 de diciembre de 1767 y 10 de julio de 1770).

86.- Sobre la labor desempeñada en Granada, así como el atentado de que fue objeto cuando abandonaba dicho destino vid. GAN GIMENEZ. P.., "Los presidentes de la Chancillería de Granada en el siglo XVIII". en Espacio, Tiempo y Forma $n^{\circ} 4$ (1988), p. 256.

87.- A.II.N. Consejos. Lib. 739.

88.- Posiblemente la falta de promoción estuviera condicionada por el caracier pusilänime de Salaverri a tenor de la definición que de èl hizo en 1765 el informante de Roda, quien dijo que aunque "su interior es tomista, pero tiene miedo a los jesuitas y partidarios, y vive acobardado".

89. - El real título que le acreditaba como tal fue expedido en Aranjuez el 25 de mayo de 1789. Cfr. A.H.N. Consejos. Lib. 739

90.- Sobre Gálvez vid. ESCUDERO, J.A., Los Secretarios de Estado y del Despacho. Madrid, 1976.

91.- Gaceta de Madrid, 6 de febrero de 1776, y 3 de julio de 1787. 